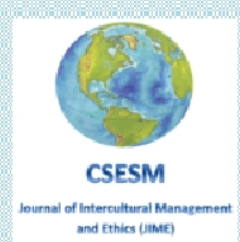

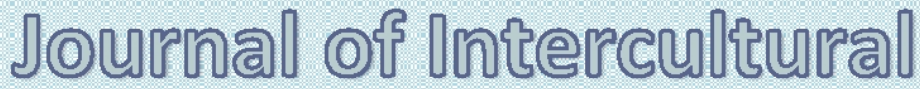

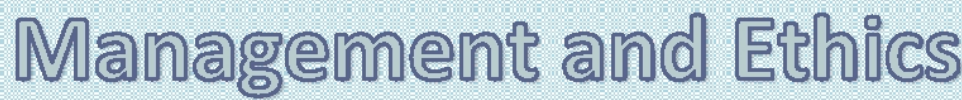

\author{
IOME
}

ISSN 2601 - 5749, ISSN-L 2601 - 5749

\section{published by zy \\ Center for Socio-Economic Studies and Multiculturalism \\ lasi, Romania \\ Waw csesmorg}




\section{Special Editor}

\section{Professor Beatrice Gabriela Ioan, PhD, MD}

Grigore T.Popa University of Medicine and Pharmacy of Iasi, Romania

E-mail: ioanbml@yahoo.com

\section{TABLE OF CONTENT}

Editorial

Beatrice Gabriela Ioan

Global Pandemics: Considerations of Public Health, Human Rights, and Bioethics

SanaLoue

Reactions of Bioethics to the Covid-19 Pandemic 19

Elena Toader, Luiza Palamaru, Tudor Stefan Rotaru, Oana Hrisca Eva

Implications of Cognitive-Behavioural Therapy in Changing Illness Representations .27

Ancuța Elena Păduraru, Camelia Soponaru

Healthcare Workers - Heroes and Villains in Covid-19 Pandemic. The Ethical

Communication

Ioana Silistraru

Ethical Dilemmas in the Therapeutic Management of Patients with Sars-Cov-2 Infection .. 45 Claudia Elena Pleşca, Ioana Hunea, Maria Obreja, Oana Stămăteanu, Delia Luchian, Irina Dima, Larisa Miftode, Tudorița Gabriela Părângă, Egidia Miftode, Simona Apostu, Camelia Bucur, Daniela Leca

Covid - 19 through the Window of Age 55

Elena Toader, Daniela Damir, Tudor Winzinger

Ethical Aspects of "Do Not Resuscitate" Orders in the Context of the Covid-19 Pandemic 61 Iulius Connor Gramma, Gema Bacoanu, Beatrice Gabriela Ioan

Ethics of the Human-Animal Relationship in the Covid-19 Pandemic .67

Cristin Coman, Diana Ancuta 


\title{
ETHICAL ASPECTS OF "DO NOT RESUSCITATE" ORDERS IN THE CONTEXT OF THE COVID-19 PANDEMIC
}

\author{
Iulius Connor Gramma ${ }^{1}$, Gema Bacoanu ${ }^{1}$, Beatrice Gabriela Ioan ${ }^{1}$ *
}

1 "Grigore T. Popa" University of Medicine and Pharmacy, Iasi, Romania

*corresponding author, e-mail:ioanbml@yahoo.com

\begin{abstract}
" Do not resuscitate" order (DNR) is issued to avoid cardio-pulmonary resuscitation (CPR) in situations when it becomes futile. Like any other medical procedure, it is based on the "maximum benefit - minimum risk" principle, on one hand, while also respecting the patient's autonomy and dignity. However, the DNR orders may be influenced by the urgency of the situation and the patient's inability to decide. The COVID-19 pandemic poses additional challenges for the decision- making process regarding resuscitation. The number of those who need intensive care is increasing daily and, implicitly, of the situations in which it is necessary to make decisions regarding resuscitation. In the meanwhile, health systems across the world are overwhelmed, lacking equipment, and medical staff. Doctors are facing the situation when they should assume, with a great moral burden, the responsibility for the DNR decision, taken unilaterally, by a pragmatic approach, justified by the potential wasting of time and resources, and exposure to the virus. Such a paternalistic approach ignores the patient's view on his/her own treatment, depriving him/her of the right to autonomy. However, when the alternative is death, whatever the risk, it should be accepted. It becomes a problem to determine the extent and conditions of such a decision. The international data on the DNR decisions taken by doctors and the criteria on which they were based are analyzed in the article. The authors conclude that when it is difficult to resuscitate all patients, and the DNR decision is ethically unacceptable, creating a protocol dedicated to the state of crisis, which would protect both doctors and patients is of critical importance.
\end{abstract}

Keywords: resuscitation, decision, patient, COVID-19 pandemic

\section{Ethical framework of the CPR and DNR orders}

Cardiopulmonary resuscitation, like any other clinical procedure, is based on 5 principles: respect for patient's autonomy, intention to act for the benefit of the patient, intention not to harm the patient, respect for patient's dignity and sincerity in dialogue with the patient. However, these principles are influenced by the urgency of the situation in which CPR must be performed and by the patient's inability to make a decision. It turns out that there may be situations in which CPR would act against the patient's interests, or would be completely useless, given the severe pathology of the patient. CPR may also determine physical injuries- such as rib fractures (Boland et al., 2015) or neurological/mental problemssuch as coma or mental decline (Chan et al., 2012). On the other hand, according to the patient's right to medical care, resuscitation is mandatory, regardless of the circumstances. The result is a conflict between the patient's right to autonomy and patient's right to medical care.

In 1995, a group of researchers have established the basic principles of DNR guidelines (Fukaura et al., 1995). Those principles regarded the steps to be taken when making such a decision, as well as recommendations once the decision was made. Diving into 
them, it is worth reminding that unless a DNR order indicates otherwise, it is presumed that life-sustaining interventions, including CPR, will be provided. This is stipulated by the patient's right to obtain reasonable care and treatment. But above all, there are the wishes of an informed patient who can make decisions that should be the primary consideration in the DNR decision given that the patient's right to autonomy is one of the basic principles of medical ethics. The physician has the responsibility of informing adequately the patient or his/her surrogate about the diagnosis and the therapeutic options. Based on the information provided by the physician, the patient or his/her surrogate should make an informed decision. The patient has the right to give an informed consent, and to do so he/she needs to be provided all the necessary information. The discussion between the health professionals, patients, and patient surrogates while making a DNR decision has to be clear, in a language accessible to the patient. Once the decision was made, it will be mentioned in the patient's medical file by the physician responsible for the patient's care. It is however not definitive. The DNR order can and should be subject to change, should any changes in the patient's medical condition occur, that resulting in a shift in circumstances and a different outcome of $\mathrm{CPR}$, if it will be required. The patient's own opinion regarding DNR might change with their condition. If the order is to be renewed or changed in any way, this aspect must be mentioned immediately in the patient's medical file. If the situation does not change, the DNR order does not mean the abandonment of the patient or that the measures for the relief of their suffering will be limited. Therefore, palliative care must be provided all the way up until the end.

\section{The legal status of the DNR orders worldwide}

The DNR order is applied to avoid performing cardio-pulmonary resuscitation in situations where it would be futile. Even before the COVID-19 pandemic, the issuance of this order was a controversial topic.

A legal basis for it has only been established by the countries where bioethics is a well-studied field, such as the United States, Great Britain, Canada, France, Japan, or Taiwan.

In the UK, CPR is presumed in the event of a cardiac arrest unless a DNR order is in place. The patient who has capacity may decline CPR based on explanation provided by the physician. Patients may also appoint a proxy for the decision-making process by means of an advance directive, which is commonly referred to as 'living will'. However, the patients and their relatives cannot ask for CPR which the doctor believes is futile. In this situation, the physician has the duty to act in the patient's best interest, based on their clinical judgment.

In the US each state accepts different forms of DNR orders. Therefore, if a patient has a living will, providing that the patient does not wish CPR, which does not have a properly filled out state-specific form, Emergency Medical Services may attempt resuscitation.

In Japan, a patient may decline CPR by means of a "Do Not Attempt Resuscitation" (DNAR) order. DNAR orders are currently used in Japan although they are not legally regulated. More, Japanese doctors and nurses are frequently involved in the decision-making process for the DNAR orders (Nakagawa et al., 2017).

\section{DNR orders in the context of the COVID-19 pandemic}

The pandemic with the new Sars-CoV-2 virus has put healthcare systems around the world under enormous pressure. First of all, hospitals have been facing a steady flow of patients in big numbers. Secondly, there is the problem of insufficient equipment, both protective (e.g. gloves, masks, gowns) and functional (e.g. intubation equipment). And probably the most serious problem raised by the pandemic is the medical staff crisis. For example, according to New York Presbyterian Hospital, a single anesthetist could perform up 
to 13 intubations per night, across the entire hospital, not just in the Emergency Department (Fins, 2021).

In addition to physical overwork, a no less important aspect is the exposure of medical staff to infection, given the large number of patients they come in contact with and the invasive procedures they perform. During the intubation of a patient with acute respiratory failure caused by COVID-19, the virus has a high risk of aerosolization, increasing its infectiousness. Thus, in Spain, at the time of April 2020, 18.5\% of the medical employees were infected with the new virus (Red Nacional de Vigilancia Epidemiológica, 2020).

Furthermore, in addition to the high degree of danger it poses to physicians, the effectiveness of CPR itself is debatable. According to statistical data from Wuhan by early April 2020, only $2.9 \%$ of patients with COVID-19 and cardiac arrest who underwent resuscitation survived (Shao, 2020). At the same time, a study by the UK National Center for Intensive Care Auditing and Research on 690 COVID-19 patients assessed the 30-day survival rate of patients intubated in intensive care units as $49.9 \%$ and mortality of patients over 70 years - 68.1\% (ICNARC, 2020). Given these data, a marked increase in the frequency of DNR orders is expected, but these decisions are often made unilaterally by doctors, based on the patient's general condition, age, and associated diseases. As it was the case, for example, in South Wales, where vulnerable patients received only a letter informing them that they would not be resuscitated (Griffith, 2020).

Indeed, from a strictly pragmatic point of view, transposing the real data in the analysis of the ratio between Risk (R) and Benefit (B), by creating an R / B equation, doctors making unilateral DNR decisions would be acceptable, when the benefit is virtually zero, the risk would be infinite. This would mean wasted time and protective equipment, and medical staff unreasonably exposed to the virus. But whatever the risk, it can be accepted when the alternative is death. In addition, such an approach is a paternalistic one, tending to ignore the patient's opinion on his/her own treatment, therefore denying them the right to autonomy. The result is a conflict between the principles of medical ethics and the brutal reality faced by the medical institutions during the pandemic.

None of the extremes is a viable solution. On one hand, trying to resuscitate all patients in serious condition caused by the COVID-19 pandemic is difficult, or sometimes even impossible, due to staff and equipment limitations. On the other hand, the DNR decision taken unilaterally by the doctor is ethically unacceptable. It becomes critical to create a balanced protocol to support this state of crisis. In order to create such a protocol, the situations when the DNR order can be applied must be established. The first such situation would be when the patient or their surrogate has made an informed decision to refuse resuscitation in case of cardio-respiratory arrest. The patient or their surrogate could also have followed the doctor's recommendation to refuse CPR by informed assent. And finally, the decision could be taken unilaterally by the physician in extreme cases where resuscitation would be completely unnecessary (situation rarely encountered before the pandemic) (Curtis, 2007).

A well-formulated informed consent would allow the doctor to take responsibility, with the approval of the patient or his/her family, for a DNR decision, if the resuscitation would not subsequently allow a quality of life acceptable to the patient. However, we must also keep in mind that, in pandemic conditions, the situation in which the patient has managed to make a decision on his/her own resuscitation can be quite rare, and determining his/her family to make a decision is usually difficult because of the psychological burden that accompanies such a decision. To determine what is "acceptable" to the patient, and to address the issue of resuscitation, the American Medical Association provides a set of instructions. According to them, the first step would be establishing the patient's values and goals, 
followed by a brief description of the role of resuscitation (how, when, and what for?) and reaching agreement between the family and physician (AMA, 2020).

In Romania, there are no legal provisions concerning the DNR orders. The state guarantees each citizen the right to health and stipulates the continuation of treatment until complete recovery or improvement of the patient's condition (Romanian Parliament, 2003) and aims to raise the patient's quality of life (Romanian Parliament, 2006). In this context, stopping therapeutic maneuvers resulting in the death of the person can easily be classified as a crime, no matter if tacitly or overtly manifested desire of the patient. This is an unfortunate situation, in the context in which until December 8, 2020 in Romania there were 524,675 confirmed cases of COVID-19 infection, of which 12,660 were deaths (INSP, 2020). Respectively, there could have theoretically been many situations requiring a DNR decision to be made.

\section{Conclusions}

The COVID-19 pandemic called for the need to review some of the approaches considered mandatory so far. In the circumstances imposed by the pandemic, the question of whether or not to apply CPR appears before doctors every day, and answers are needed. Establishing a legislative basis for making such decisions can help considerably in getting out of this crisis situation, of course, while respecting fundamental values and ethical principles.

\section{References}

Boland, L.L., Satterlee, P.A., Hokanson, J.S., Strauss, C.E. \& Yost, D. (2015). Chest Compression Injuries Detected via Routine Post-arrest Care in Patients Who Survive to Admission after Out-of-hospital Cardiac Arrest. Prehospital Emergency Care, 19(1), 23-30.

Chan, P.S., Spertus J.A., Krumholz, H.M., Berg, R.A., Li, Y., Sasson, C. \& Nallamothu, B.K. (2012). Supplement of a validated prediction tool for initial survivors of in-hospital cardiac arrest. Archives of Internal Medicine, 172 (12), 947-53.

Curtis, J. R. (2007). Point: The Ethics of Unilateral "Do Not Resuscitate" Orders. Chest, 132(3), 749-750.

Fins, J. J. (2021). Resuscitating Patient Rights during the Pandemic: COVID-19 and the Risk of Resurgent Paternalism. Cambridge quarterly of healthcare ethics: CQ: the international journal of healthcare ethics committees, 30(2), 215-221.

Fukaura, A., Tazawa, H., Nakajima, H., \& Adachi, M. (1995). Do-not-resuscitate orders at a teaching hospital in Japan. New England Journal of Medicine, 333,805-8.

Griffith, R. (2020). COVID-19 and the lawfulness of bulk do not attempt resuscitation orders. British Journal of Nursing, 29(17), 1042-1043.

Institutul Național de Sănătate Publică România- INSP (2020). Situație infecții coronavirus (COVID 19)- 8.12. 2020 [Coronavirus infection situation (COVID 19) - 812 2020]. http://www.cnscbt.ro/index.php/situatia-la-nivel-global-actualizata-zilnic/2141situatie-infectii-coronavirus-covid-19-8-12-2020

Intensive Care National Audit \& Research Center - ICNARC (2020). Report on COVID-19 in critical care, April 4, 2020. ICNARC COVID-19 report 2020-04-04. https://www.icnarc.org/Our-Audit/Audits/Cmp/Reports.

Nakagawa Y., Inokuchi, S., Kobayashi, N., \& Ohkubo, Y. (2017). Do not attempt resuscitation order in Japan. Acute Medicine \& Surgery, 4(3), 286-292.

Red Nacional de Vigilancia Epidemiologica. Informe núm. 22. Situación de COVID-19 en $\begin{array}{llllll}\text { España } & a & 13 & \text { de } & \text { abril }\end{array}$ https://www.isciii.es/QueHacemos/Servicios/VigilanciaSaludPublicaRENAVE/Enfer medadesTransmisibles/Paginas/InformesCOVID-19.aspx. 
Romanian Parliament. (2003). Law 46/2003 on the patients' rights. The Official Monitor no. $51 / 29^{\text {th }}$ of January 2003. www.legisplus.ro.

Romanian Parliament. (2006). Law no. 95/2006 on reform in healthcare system- republished. The Official Monitor no. 652 / $28^{\text {th }}$ of August 2015. www.legisplus.ro

Shao, F., Xu, S., Ma, X., Xu, Z., Lyu, J., Ng, M, et al. (2020). In-hospital cardiac arrest outcomes among patients with COVID-19 pneumonia in Wuhan, China. Resuscitation, 151, 18-23 